\title{
EENE BIJDRAGE TOT DE PALAEOGRAPHIE VAN NEDERLANDSCH INDIE.
}

Het was aan allen die belang stelden in de Indische oudheid welbekend dat de Heer K. F. Holle sedert eenige jaren bouwstoffen verzamelde voor eene vergelijkende tabel van Indische schriftsoorten. De telken jare aangroeiende stof, een gevolg van nieuwe vondsten en van verhoogde belangstelling in de Indische epigraphie, is de oorzaak geweest dat de Heer Holle zijn werk gaandeweg heeft uitgebreid en aangevuld, hetgeen onvermijdelijk gepaard is gegaan met een vertraging der uitgave. Eindelijk is de "Tabel van Oud- en Nieuw-Indische alphabetten" verschenen '. Terecht heeft de bewerker begrepen dat langer uitstel niet in het belang der zaak zou wezen, al erkent hij dat de tabel op verre na nog geen afgerond, geordend geheel vormt, en al deelt hij ons mede dat hij nog een 50 tal alphabetten, en daaronder zeer belangrijke, is machtig geworden, waarvan in de tabel nog geen gebruik is gemaakt. Een tweede tabel is dan ook reeds in bewerking.

De verzameling die ons in de thans reeds verschenen tabel wordt aangeboden omvat niet minder dan 198 alphabetten, waarvan de oudste dat is, hetwelk voorkomt op de edicten van Koning Açoka, anders genaamd Priyadarçin (Piyadassi), van omstreeks 250-225 vóór Chr. Het rijkst vertegenwoordigd zijn de oudere en nieuwere Indische schriftsoorten in den Archipel gebruikelijk. Het eigenlijke doel dat de Heer Holle zich voorgesteld en bereikt heeft, was een overzicht te geven, zoo volledig als te gegevener tijd mogelijk, van de alphabetten op de

1 De volledige titel is: Tabel van Ond- en Nieuw-Indische alphabetten. Bijdrage tot de Palaeographie van Nederlandsch-Indië, door K. F. Holle. Uit. gegeven door het Bataviaasch Genootschap voor Kunsten en Wetenschappeu. Batavia, W. Bruining \& Co. 's Gravenhage, M. Nijhoff, 1882. De steendruk der platen is van C. Lang te Buitenzorg.

4e Volgr. VI. 
eilanden van den Archipel, terwijl de lettervormen die in Vooren Achterindië gebruikelijk waren, en zijn, slechts dienen moeten ter vergelijking met, en ter verklaring van, de gewijzigde vormen welke wij in het schrift der eilandbewoners ontmoeten.

In eene palaeographie van Nederlandsch-Indië moet uit den aard der zaak de grootste plaats worden ingeruimd aan de varieteiten van het Kawi-alphabet, want daarvoor zijn de meeste bouwstoffen voorhanden. Men kan met volle handen putten uit inscripties op steenen, koperen platen, ringen, en uit oude handschriften, zoodat men een vrij volledig overzicht kan geven van de varieteiten van Kawi-schrift zooals dat van omstreeks 800-1500 na Chr. op Java gebruikt werd. Uit de opgegeven bronnen, zooals inscripties enz., heeft de Heer Holle eene verzameling van 40 soorten opgenomen, kolom $38-48$; 51-53; $76-79 ; 82-94 ; 110 ; 162-169$; van de nieuwere Javaansche en Soendaneesche schriftvormen zijn er ook verschillende soorten medegedeeld; daarenboven zijn er Oud-javaansche alphabetten, bij Raffles opgegeven, opgenomen, alsook die welke Cohen Stuart in het Tijdschrift van 't Koninklijk Instituut v. Taal-, Land- en Volkenkunde (D. IV, 1863) heeft laten afdrukken, klaarblijkelijk uit Raffles getrokken. Deze laatsten waren dus overbodig, want ze zijn slechts eene kopie. Noch de opgave van Raffles, noch de kopie kan in allen deele als juist beschouwd worden; zoo, om een voorbeeld te noemen, kan ik zonder nader bewijs niet gelooven dat de letter als dentale $t a$ opgegeven in kolom 60 (Raffles) en kolom 69 (Cohen Stuart) werkelijk is, waarvoor ze wordt uitgegeven; klaarblijkelijk is de bedoelde letter van Raffles dezelfde als de linguale $t a$ van kolom 69. Er zijn nog meer verdachte zaken in die twee tabellen, die ik hier met stilzwijgen voorbijga. Het is jammer dat de Heer Holle voor het merkwaardige schrift van kol. 62 en $63(=$ kol. 71 en 72$)$, hetwelk het midden houdt tusschen het oudere Kawi-schrift en het nieuwere Javaansche, geen handschriften heeft kunnen raadplegen. Die handschriften zijn anders niet zeldzaam; ze hebben meestal dit eigenaardige dat zij, als talismans door de Javanen beschouwd, bij het haardvuur schijnen bewaard te zijn geworden, want ze zien er gewooonlijk erg berookt uit en zijn soms half verbrand. Uit den inhoud blijkt dat ze uit den heidenschen tijd dagteekenen, vermoedelijk uit het begin der 16de eeuw, toen Java, althans het oostelijk gedeelte, nog grootendeels 't heidendom 
beleed, zooals uit de berichten der Portugeezen bekend is. Mogelijk zijn die handschriften nog ouder en moeten ze tot de $15^{\text {de }}$ eeuw gebracht worden, ofschoon èn taal èn schrift jonger zijn dan de Kawi-handschriften uit de Soenda-landen, waarover de Heer Holle op bl. 15 zijner inleiding spreekt.

Sumatra is vrij volledig vertegenwoordigd door het Lampongsche, Bataksche en Redjangsche schrift. waarbij nog te voegen is dat van Kommering, Abong en Pasĕmah, in 't geheel 20 kolommen. Van het oude Sumatraansehe schrift kan niets anders medegedeeld worden dan wat voorkomt op de inscripties van Adityawarman (kol. 112 en 113).

Behalve de Kawi-type en wat daaruit ontstaan is, bestaat er, gelijk eerst sinds eenige weinige jaren bekend is, een oudere, aangetroffen in West-Java en in Koetei. Van eene jongere schriftsoort, weinig verschillende van het Nâgarî, zijn er ook enkele voorbeelden op Java ontdekt. De drie hoofdtypen, waartoe volgens den heer Holle 1 alle alphabetten van Ned. Indië, voor zooverre ze van Indischen oorsprong zijn, kunnen gebracht worden zijn: I. de Câlukya of Wenggi-type; II. de Kambodjatype; III. de Nâgarî-type.

In hoofdzaak ben ik het met den heer Holle eens, alleen twijfel ik er aan, of de derde type wel ooit op Java inheemsch geweest is; zij wordt gevonden op aangebrachte voorwerpen en op een paar inscripties, maar zulke inscripties leveren, mijns inziens, reeds door het feit dat ze in een vreemd alphabet geschreven zijn, het bewijs dat ze afkomstig zijn van Hindus, en meer bepaaldelijk dezulken, die zich van Nâgarî-schrift bedienden. Zulke, uiterst zeldzame inscripties, staan tot de echt Javaansche juist in dezelfde verhouding als bijv. de Burmeesche letters van het opschrift te Buddha Gayâ tot de andere daar ter plaatse gebruikelijke. Nu weten wij met zekerheid dat bedoeld opschrift door Burmeezen is aangebracht, en we mogen veilig aannemen dat een dergelijk geval zich nu en dan op Java heeft voorgedaan.

Omtrent het Boegisch-Makassaarsch schrift laat de schrijver in de inleiding, blz. 6 , zich eenigszins aarzelend uit. Inderdaad hebben de Makassaren en Boegineezen het alphabet zóó vereenvoudigd, dat zij meer dan de helft er van hebben afgeschaft, en zóó verminkt, dat sommige letters onherkenbaar zijn ge- 
worden. Vergelijkt men echter de typen met de Lampongsche, dan is, dunkt mij, de verwantschap toch wel te herkennen. De Mak. $k a$ is eene verminking van de Lampongsche $k a$; de ga evenzoo; de stip is een noodhulp om de letter te onderscheiden van de $p a$; de $n g a$ is eene vereenvoudiging van Lamp. kol. 121, terwijl de sierlijkere, oudere Mak. vorm te verklaren is uit Lamp. kol. 119; de $\boldsymbol{c a}(\mathrm{tja})$ is te vergelijken met Lamp. kol. 121 en 122; de $j a$ (dja) met Lamp. kol. 120, verminkt; de $\tilde{\mathrm{n} a}$ is Lamp. 116, 117 en 119; dat de krul onderaan niet bij de letter behoort en dus slechts dient om ze te onderscheiden van de $w a$, blijkt uit het oudere Mak. karakter, waaraan die krul ten eenenmale ontbreekt. De $t \boldsymbol{a}$ is een verminkte Lamp. kol. 117, de $d a$ een dito kol. 121; de oudere Mak. $d a$ is wel bezien niets anders dan Lamp. kol. 123, van boven aan den linkerkant omgekruld of doorgetrokken. De $n \boldsymbol{a}$ is eene vereenvoudigde Lamp. $n \boldsymbol{a}$; de stip dient slechts om de letter te onderscheiden van de $t a$. De $p a$ is de Lamp. $p a$; de $b a$ is Lamp. kol. 116-121, terwijl de sierlijkere, vollere oude Mak. $b a$ aan Lamp. kol. 115 beantwoordt. De $m a$ is te vergelijken met Lamp. kol. 115, en de oude Mak vorm met Lamp. 117 en Kroeing 129. De $y a$ is de Tampongsche, doch voorzien van een paar puntjes om ze te onderscheiden van $w a$; de $r a$ is eene eenigszins gewijzigde Lampongsche of Battaksche $r a$; de $l a$ komt ook met de Lampongsche overeen, behalve dat er van boven een streep bijgevoegd is; de $w a$, ten minste de oudere, laat zich uit Lamp. kol. 115 verklaren, als men het onderstuk afrondt en den mond van boven nauwer maakt; de nieuwe Mak. $w a$ toont verwantschap met Lamp. kol. 116 en Pasĕmah kol. 127; de oudere $s a$ kan licht ontstaan zijn uit Lamp. kol. 118 , de jongere uit kol. 117, hoewel deze laatste type eigenlijk niet $s a$ maar ça schijnt te wezen; de $a$ is Lamp. 120, met dit verschil dat de korte streep links van onderen geworden is een stip rechts.

Veel moeielijker dan de verklaring van 't MakassaarschBoegisch alphabet is die van 't Bimasche, met uitzondering van hetgeen in de eerste der drie kolomme (138-140) gegeven wordt, want dat schrift, niettegenstaande het volgens Raffles en Friedrich een oud alphabet heet, is niets anders dan 't hedendaagsche Makassaarsch-Boegineesche, verrijkt met ettelijke letters die de Makassaren en Boegineezen niet behoeven. Met de karakters in kol. 139 en 140 vertoonen die in kol. 
138 oppervlakkig beschouwd weinig overeenkomst, behalve bij uitzondering zooals bij de $w a$ het geval is. Doch zoodra het oog zich aan de krullige oud-Bimasche letters gewend heeft, ontwaart men dat $w a$ kol. 139 eene sierlijk getrokken Lampongsche en Redjangsche $w a$ is. Ook de ya laat zich wel met de Lampongsche vergelijken, mits men de eerste krul wegdenkt; de Bimasche $k a$ bij Raffles (kol. 140) is in hoofdzaak de Lampongsche $k a$, maar overladen met krullen; hetzelfde geldt van ja (dja) vergeleken met Lamp. kol. 122, alsook van $d a$ vergeleken met Lamp. kol. 121, 124 en 125; nda met Pasĕmah nda kol. 127. De $s a$ laat zich herkennen in Pasĕmah kol. 127, tweede vorm; in Lamp. 116, 119, 120. De $m a$ toont overeenkomst met de oudere Makassaarsche, en dus ook een der Lampongsche en Kroeingsche. Hoewel ik niet van alle oudBimasche letters het verloop kan naspeuren, hel ik, alles te zamen genomen, er toe over te gelooven, niet alleen dat ze van Sumatraansche herkomst zijn, maar ook dat zij in menig opzicht de oudere trekken vertoonen van een schrift, waaruit zich later de Makassaarsch-Boegineesche typen ontwikkeld hebben. Met andere woorden, ik kom tot het besluit dat het schrift van Makassaren, Boegineezen en Bimeezen van den beginne af identisch is geweest, en dat het ontleend is aan 't oude Maleische alphabet, hetwelk in jongeren en gewijzigden vorm in de Lampongs, bij de Rĕdjangers en in Pasěmah voortleeft.

Deze uitkomst waartoe de onderlinge vergelijking van Makassaarsch-Boegisch-Bimasch schrift met dat van Midden- en Zuidelijk Sumatra mij geleid heeft, staat zeker niet zoo onomstootelijk vast dat verder onderzoek overbodig mag heeten, en ik geef nog volstrekt de hoop niet op dat er vroeger of later de schakels die er nu nog ontbreken zullen geworden worden. In allen gevalle geloof $\mathrm{ik}$ dat wij met de ons thans ten dienst staande gegevens geen ander besluit mogen trekken.

Het ligt niet in mijn plan hier uit te weiden over het nauwe verband tusschen het Kawi-alphabet en dat van Kambodja uit het tijdperk van Sûryawarman, vooreerst omdat ik reeds elders daarover gesproken heb, en ten andere omdat de heer Holle daarvan evenzeer overtuigd is als ik. Trouwens niemand die de beide alphabetten kent zal er aan twijfelen. Toch zijn er enkele punten die ik moet aanroeren, omdat het bewijs van die nauwe verwantschap eerst in de laatste twee of drie jaren kon geleverd worden en omdat ik, lang vóórdat de Kambodjasche 
opschriften ontcijferd waren de meening was toegedaan dat het Buddhisme op Java niet ingevoerd was uit Achter-Indië, maar uit Orissa of Bengalen. In de inleiding bl. 7 haalt de schrijver de volgende woorden van mij aan:

"Zoo wel het Sumatraansch rotsopschrift als de op Java aan het licht gekomen gedenkstukken, o. a. 't beeld van Mañjuçrî, leveren het bewijs dat de (Buddhistische) leer, zooals die in de 14de eeuw op Java en Sumatra bloeide, dezelfde was als die der Noordelijke Buddhisten. Daaruit volgt dat het Buddhisme op de Soenda-eilanden niet is ingevoerd uit Ceilon of AchterIndië, maar uit Bengalen, Orissa of eenig ander deel van Noordelijk Indië."

Bijna alles wat hier gezegd is, blijft ook nu waar; de Buddhisten op Java en Sumatra behoorden tot de Noordelijke afdeeling 1 der Kerk; de gevolgtrekking dat de leer dus niet uit Ceilon was ingevoerd, is ook juist; maar dat ze niet uit Achter-Indië kon overgebracht zijn, blijkt onjuist te zijn. Aangezien tegenwoordig de Burmeezen en Siameezen tot de Zuidelijke Buddhisten behooren, wier heilige boeken in het Pâli opgesteld zijn, en niemand vóór drie jaren nog wist dat in Kambodja oudtijds het Noordelijk Buddhisme heerschte, was het zeer verklaarbaar dat ik ook Achter-Indië uitsloot. $\mathrm{Nu}$ echter uit verschillende feiten is gebleken dat de Buddhisten in 't land der Khmers of Kambodja tot de Noordelijke afdeeling der Kerk behoorden ${ }^{2}$, bestaat er niet de minste reden om te veronderstellen dat het Buddhisme op Java en Sumatra zich niet uit Achter-Indië, meer bepaaldelijk Kambodja, zou uitgebreid hebben. Dat verder de Kambodjasche Buddhisten uit Orissa of noordelijker streken moeten gekomen zijn, laat zich vooralsnog niet aantoonen, maar zooveel is zeker dat de oudste Achter-indische plaatsnamen, zooals Indraprastha en Ayodhyâ, zeer bepaaldelijk en ondubbelzinnig Noordelijk Indië aanwijzen als het land waaruit de Arische kolonisten gekomen zijn, zoodat de Indische beschaving een geheel anderen weg schijnt genomen

1 De naam is niet gelnkkig gekozen, zooals men ziet, maar het is bekend wat er mede bedoeld is.

2 De tegenwoordige bewoners hebben niet de minste heugenis meer van de toestanden daar te lande nauwelijks 1000 jaar geleden, evenmin als van de oprichters der prachtige gebouwen, wier bestaan door den ijver der Fransche geleerden aan ' $t$ licht is gebracht. De zoogenaamde Siameesche geschiedkundige berichten, waarvan Pallegoix spreekt, staan nog beneden de Javaansche Babads. 
te hebben dan men oppervlakkig verwachten zou. Ook is uit de vondst van het Buddhistische geloofsformulier in Nâgarîschrift op Java gerust het besluit te trekken dat het verkeer tusschen de Javaansche en Noord-Indische Buddhisten nog lang voortgeduurd heeft.

Het behoeft wel niet gezegd te worden dat niettegenstaande de groote zorg aan de voortreffelijk geteekende tabel besteed, er hier en daar eenige kleinere onjuistheden in voorkomen. Een paar wil ik er aanstippen. In kol. 80 wordt het teeken voor den Upadhmânîya in de Sanskrit inscriptie van Djamboe als Pěpět opgegeven; de vorm van het teeken is wel dezelfde als die van de $\check{e}$ in een menigte Kawi-inscripties, maar de waarde is een geheel andere, en wel die van een Wisarga vóór de $p$ en $p h$.

De $e$ van kol. 43 is niet het klinkerteeken van de $e$, maar van de $a i$ (eigenlijk $a i$ ); te recht wordt die waarde er aan gehecht in kol. 48. Het teeken voor de $\hat{u}$ (oế) zoek ik te vergeefs onder de kolommen voor het Kawi-schrift, hoewel het zeer vaak voorkomt, soms zelfs verkeerdelijk in plaats van de korte $u$ (oe), gelijk in Javaansche poëzie regel is geworden, wanneer de lettergreep aan 't einde van een versregel staat. Voor de Philippijnsche talen kol. 170 wordt als $e$ en $o$ opgegeven, wat $i$ en $u$ is ; de oorzaak daarvan ligt in de omstandigheid dat de Philippijners $e$ en $i, o$ en $u$ met elkander in de uitspraak verwarren, hetgeen niet wegneemt dat zij steeds $i$ en $u$ schrijven, al spreken zij die dan ook als $e$ en $o$ uit. Ook het teeken voor $r a$ in kol. 170 stelt niet de ware $r a$ voor, maar de $d a$ of $d a$, terwijl de door Tagalas en Bisayas als $l a$ uitgesproken letter als $r a$ had moeten opgegeven zijn; ofschoon thans die talen den klank der ra verloren hebben, het teeken bezitten zij nog.

Alvorens te eindigen moet ik den lezer opmerkzaam maken op hetgeen in de inleiding bl. 12 gezegd wordt omtrent het gebruik van de $n g$ instede van den Anuswâra. Tengevolge van mijn minder duidelijk schrift heeft de heer Holle opgemaakt dat ik van den Anuswâra vóór $g(m)$ en $s$ sprak; ik bedoelde echter vóór $c ̧(m)$ en $s$; de combinatie $\stackrel{a}{a} \boldsymbol{m}$ is regelmatig en algemeen Indisch; daarvan was geen sprake.

Met behulp van de tabel is iedereen, met goeden wil, in staat om de Oud-Javaansche en Oud-Soendaneesche inscripties

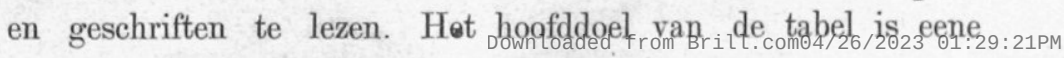


palaeographie te leveren voor de talen van den Indischen Archipel; aan dat doel beantwoordt het werk volkomen. Daarom zij onze warme dank gebracht aan den onvermoeiden vervaardiger, die geene moeite ontzien heeft om het zijne bij te dragen tot grondiger kennis van hetgeen vroegere geslachten in den Indischen Archipel gewrocht hebben. In 't verleden ligt het heden, en wie meent dat hij ook wel buiten dat verleden het tegenwoordige best kan doorgronden, zal licht gevaar loopen het hedendaagsche van een verkeerd standpunt te beschouwen.

H. Kern. 